\title{
MARGENS DA POLÍTICA, FRONTEIRAS DA VIOLÊNCIA: UMA AÇÃO COLETIVA DAS PERIFERIAS DE SÃO PAULO
}

\author{
Gabriel de Santis Feltran
}

\section{Apresentação}

"Manhã de dezembro. Desço a pé as vielas fechadas de uma favela do Parque Santa Madalena, zona leste de São Paulo. Estou acompanhado de dois militantes do Centro de Direitos Humanos de Sapopemba (CDHS) e de uma freira da Eritreia. Ela me conta que os cristãos são perseguidos em seu país, que se sente em casa nas favelas, que a luta dos movimentos populares 'é a mesma no mundo todo'. Universalismos... pensei comigo. Pedimos licença a moradores sentados na soleira de suas portas; eles nos abrem caminho sem nenhum entusiasmo. Depois de passarmos, um deles grita: 'Tempo de política vem todo mundo pagar pau, não é não!?’. Um ano eleitoral viria pela frente, de fato. No ponto mais baixo e central da favela - que ocupa duas encostas íngremes - se aglomeravam umas vinte pessoas, alguns rostos conhecidos, formando uma roda.

Valdênia Paulino - a militante mais conhecida da região, diretora do CDHS - falava aos moradores no microfone: 
'Vamos descer, pessoal, para participar dessa conversa, para mostrar que em Sapopemba a gente sabe receber as visitas com calor humano!'. Explicava que se tratava de um ato contra a violência policial, e citava nomes de adolescentes dali assassinados pela polícia. 'Lembram do Vandinho? E do Jackson da D. Nenê? [nomes fictícios]. Estamos aqui em nome deles, pela memória deles!'. Valdênia falava com propriedade, conhecia os meninos, suas mães e suas histórias. Era muito respeitada na favela.

O evento lançaria um relatório da Anistia Internacional sobre o policiamento em 'comunidades' no Brasil, chamado 'Eles entram atirando'. As pessoas foram chegando; entre moradores e 'gente de fora', já éramos quase cem. A roda crescia e um grupo de samba do Centro de Defesa dos Direitos de Crianças e Adolescentes (Cedeca) dava o tom. Valdênia começou 202 então a convocar os presentes para fazerem depoimentos públicos: duas vítimas de violência policial, depois o coordenador das Comunidades Eclesiais de Base (CEBs) do distrito; em seguida o presidente de honra do CDHS, uma militante do Rio de Janeiro, outra de São Bernardo do Campo e mais uma de Guarulhos. Parentes de vítimas de violência policial de várias cidades brasileiras estavam ali. Um pastor da igreja evangélica também compareceu; representantes do movimento dos sem-teto e de diversas entidades civis de defesa de direitos foram anunciados. Por último, anunciou-se a presença de uma série de parlamentares, todos do Partido dos Trabalhadores (PT): um vereador, dois deputados estaduais e dois federais. Cada uma destas pessoas sentou-se numa roda em torno de milhares de cartas espalhadas pelo chão, que narravam casos de violência policial do mundo todo. Cada um fez uma intervenção curta, seguida de aplausos. A cena era tocante. 
Pensei comigo, escrevendo essas notas: Valdênia era o único elo de relação entre toda aquela gente. Eu mesmo estava ali por seu intermédio." (Notas de campo).

Nas últimas três décadas, as ações coletivas de moradores das periferias de São Paulo - e de outras grandes cidades brasileiras - ocuparam invariavelmente um espaço normativo de mediação entre a população mais pobre da cidade, de um lado, e o mundo das instituições políticas, de outro. O evento na Favela do Madalena e a função nele desempenhada por Valdênia expunham com clareza essa condição. Entretanto, se o lócus de atuação dessas ações coletivas permaneceu o mesmo desde os anos 1970, o sentido da mediação que desempenham modificou-se radicalmente, desde então. Ao menos duas linhas de transformações, associadas, sintetizam essa mudança. De um lado, a da transição do regime político dos anos 1980, que nos anos 1990 inseriu subalternamente os movimentos sociais das periferias na política institucional; e, de outro, a transformação expressiva no perfil da população dessas periferias nas últimas décadas, que questionou a capacidade representativa daqueles atores.

A aposta deste texto é que o estudo da trajetória mediadora de uma dessas ações coletivas permite colocar essas duas linhas de transformação em relação, iluminando as fronteiras (ou margens) da política contemporânea no Bra$\operatorname{sil}^{1}$. O artigo toma a trajetória de mais de duas décadas do Cedeca Sapopemba, uma entidade de defesa de direitos da periferia leste de São Paulo, como objeto heurístico dessa reflexão. Argumento que essa relação entre periferias e

\footnotetext{
${ }^{1}$ Discuto a categoria analítica "fronteira" mais adiante e em Feltran (2008). Das e Poole (2008) utilizam a noção de "margens" do Estado moderno em sentido tanto descritivo quanto crítico, recuperando três usos recorrentes do conceito: margens da legalidade oficial; margens da legibilidade estatal (por referência à burocracia escrita); e margens da normalidade (relação entre corpos, lei e disciplina), tendo por referência o biopoder foucaultiano.
} 
mundo público foi historicamente marcada pelo conflito. O percurso desse conflito, bem como de suas formas de contenção a partir dos anos 1970, faz ainda hoje coexistirem na cena pública três dispositivos distintos, que na linha do tempo tiveram ênfases sucessivas: 1) a luta política, cuja lógica interna remeteu à aposta nos direitos da cidadania, central nas ações dos "movimentos sociais" dos anos 1980 e início dos 1990; 2) a gestão social, gerenciamento estatal e não governamental de populações específicas das periferias, muito presente na lógica interna dos "programas sociais" a partir de meados dos anos 1990; e 3) a violência, presente ou latente na repressão policial às periferias e regulada hoje, sobretudo, pelo próprio "mundo do crime", em expansão nas periferias da cidade. A diferenciação entre os dispositivos, aqui, é meramente analítica: pretende conferir inteligibilidade a dinâmicas que coexistem, com centralidade sucessiva, na trajetória do Cedeca. A argumentação do texto 204 está amparada em etnografia realizada entre 2005 e 2009 no distrito de Sapopemba, zona leste de São Paulo ${ }^{2}$.

Como se sabe, há trinta anos o mundo político brasileiro gravitava em torno de um regime ditatorial e, portanto, refratário por definição à participação política pluralista. Ao mesmo tempo, a modernização e o pleno emprego industrial daquele período - conhecido como "milagre econômico" - atraíam milhões de migrantes de todo país para as periferias das metrópoles. O perfil da população que ocupou essas periferias foi, por essas duas razões, majoritariamente migrante e centrado na família extensa, cuja expectativa era "melhorar de vida" na cidade. A coesão social dessa população se ancorava nos valores católicos e no projeto

\footnotetext{
${ }^{2}$ Sapopemba é um dos 96 distritos do município de São Paulo e faz fronteira com Santo André. São 300 mil habitantes em região de "periferia consolidada" da cidade (urbanização elevada e crescimento demográfico). Há 37 favelas no distrito e metade dos domicílios tem chefes de família com renda inferior a três salários mínimos.
} 
de mobilidade social ascendente pelo trabalho industrial ${ }^{3}$. A demanda por integração social e representação política dos interesses desses trabalhadores era intensa, embora reprimida. A promessa pública, no entanto, era a de que a modernização do país inscreveria essas "classes trabalhadoras" na dinâmica salarial, e que a contrapartida social do assalariamento, $\mathrm{o}$ acesso a direitos sociais, geraria melhoria objetiva nas condições de vida das famílias.

Para que a promessa se efetivasse, no entanto, não bastava apenas o esforço privado do provedor da família. Era preciso garantia estatal do emprego e dos direitos a ele associados; portanto, exigia-se que um projeto político estivesse associado ao projeto familiar operário. Não por acaso, percebeu-se logo a necessidade de constituição de ações coletivas para representar essa gente: os "novos movimentos sociais" das periferias emergiram, desde o final dos anos 1970, como portadores desse anseio de integração da "classe trabalhadora" na dinâmica da "cidadania" que se anunciava renovada pela abertura do regime ${ }^{4}$.

Mais de três décadas depois, esses parâmetros da experiência coletiva das periferias urbanas se deslocaram substantivamente ${ }^{5}$. Do ponto de vista político-institucional, lá se vão 25 anos de regime formalmente democrático e do estabelecimento de um sistema ampliado de participação civil nas políticas públicas - a "inovação institucional" da "democracia participativa" brasileira foi enormemente debatida na academia ${ }^{6}$. Sob o prisma da dinâmica social

\footnotetext{
${ }^{3}$ A "família operária" e seus desdobramentos políticos foram estudados exemplarmente por Durham (2005) e Caldeira (1984).

${ }^{4}$ Baierle (1992), Doimo (1995) e Paoli (1995) fazem revisões bibliográficas importantes sobre os movimentos sociais do período em São Paulo. Dagnino (1994; 1995) analisa especificamente o papel da noção de cidadania entre eles.

${ }^{5}$ Marques e Torres (2005) compilam estudos recentes dessas transformações em São Paulo.

${ }^{6}$ Dagnino e Tatagiba (2007) recuperam as linhas gerais desse debate na contemporaneidade.
} 
das periferias, entretanto, as transformações (também nada triviais) são bem menos comentadas. As três últimas décadas foram palco de um câmbio geracional que, concluído, demonstrou uma mudança expressiva nos pilares da vida social desses territórios. Quem reside hoje nas fronteiras da cidade não é mais migrante, é "paulistano". Meus interlocutores de pesquisa com menos de 30 anos se dizem comumente "nascidos e crescidos aqui na zona leste mesmo"; "aqui no Madalena”. A organização de suas famílias, mais tipicamente urbanas, também respondeu à tendência de transformação intensa ${ }^{7}$. No plano religioso, em apenas duas décadas milhões de católicos transitaram à teologia neopentecostal, bastante conectada às transformações em curso nesses territórios ${ }^{8}$. A capacidade de consumo, já não diretamente vinculada à renda pela expansão do crédito popular, aumentou muito mesmo nas favelas ${ }^{9}$. Novas tecnologias de informação favoreceram a conexão 206 dos moradores jovens das periferias a espaços de construção identitária renovados, e acesso a universos inimagináveis há alguns anos ${ }^{10}$.

Oferecendo pano de fundo a essas transformações está o deslocamento no centro de gravitação do projeto operário: o trabalho industrial, radicalmente modificado pelo que se convencionou chamar de "reestruturação produtiva”. Crises severas do emprego, sobretudo nos anos 1990, e a estabilização do desemprego estrutural forçaram mudan-

\footnotetext{
${ }^{7}$ Sobre família e religiosidade nos meios populares contemporâneos, ver Duarte e Helborn (2006) e Duarte e Gomes (2008).

${ }^{8}$ Sobre o fenômeno neopentecostal, ver Almeida (2004; 2009).

9 Apenas no ano de 2009 as classes D/E ampliaram em $17 \%$ o consumo de produtos não duráveis e em 16,8\% o de duráveis. O aumento, mesmo em ano de crise financeira, consolida tendência na década, acelerada nos últimos anos (Aragão, 2009).

${ }^{10}$ As lan-houses representam a principal forma de acesso à internet no Brasil. Na última década, a indústria cultural e do entretenimento estabeleceu nichos de produtos voltados especificamente para os jovens das periferias (programas de televisão, sites de relacionamento, música, vestuário, acessórios etc.).
} 
ças significativas do mercado de trabalho popular. Se em 1970 era fácil conseguir um emprego fabril, em 2010 esse emprego é escasso e exige alta escolaridade, além de especialização e flexibilidade; ainda assim, quem chega a ele em geral ocupa postos terceirizados e pouco estáveis. O espaço da fábrica que antes, pela sindicalização crescente, favorecia a construção de identidades e ações coletivas, se traduz nos anos 2000 em espaço competitivo por incentivos seletivos.

A promessa de mobilidade social operária se traduziu, já em época toyotista, no sucesso de uma pequena elite das periferias que apostou no sobretrabalho e na formação escolar dos filhos como alavancas de ascensão à classe média ${ }^{11}$. Para a grande maioria dos filhos de operários fordistas que encontro em pesquisa, entretanto, a contrapartida social do assalariamento nunca chegou ${ }^{12}$. Diversas investigações recentes entre jovens moradores das periferias encontram mais frequentemente trajetórias de inserção ocupacional instável, sobretudo no setor de serviços ou em empregos terceirizados. Nas franjas desse mercado de trabalho, aparecem os trabalhos liminares entre o formal, o informal e o ilícito ${ }^{13}$. Sobretudo entre os moradores de favela, os mercados que se expandem são não apenas desprotegidos, caso da terceirização industrial a domicílio ou da catação de materiais recicláveis, como frequentemente ilegais, caso do varejo de drogas ilícitas. Nesse cenário, o "mundo do crime", antes considerado o oposto diametral dos "trabalhadores", surge recentemente como a atividade melhor remunerada e com alta disponibilidade de "postos de trabalho" para jovens de favela. Além disso, "o cri-

\footnotetext{
${ }^{11}$ A geração é categoria analítica central na excelente análise do mundo operário de Beaud e Pialoux (2003; 2009).

${ }^{12}$ As classes D/E ainda somavam $39 \%$ da população brasileira em 2008. Sobre a reestruturação produtiva no país, em perspectiva comparada, ver Guimarães (2009a; 2009b); sobre a frustração da promessa operária de mobilidade e a questão da violência, ver Machado da Silva (2004) e Misse (2006).

${ }^{13}$ Ver Telles e Cabanes (2006), Ferreira (2003) e Guimarães (2004).
} 
me" passa a ser legitimado progressivamente como instância normativa e fiscal das regras de convívio ${ }^{14}$.

Em suma, na etnografia em favelas e periferias da cidade tem sido possível reconhecer impactos causados tanto pelas mudanças na institucionalidade política quanto no mercado de trabalho, na família, na religiosidade, no consumo e no projeto de mobilidade social. Em meio a essas transformações, entretanto, a desigualdade entre pobres e ricos atravessa as três últimas décadas intocada. A frustração da perspectiva de "integração" social da população desses territórios na dinâmica de "desenvolvimento" do Brasil é, portanto, inevitável. Nessa frustração, assumida como "realidade" pela geração jovem, é todo um projeto coletivo que deve ser revisto ${ }^{15}$. E quando o projeto coletivo de "estar no mundo" se modifica, os atores tradicionais de representação desse projeto, como os movimentos sociais, são postos em questão. Se no cenário anterior a mediação das deman208 das das periferias ao mundo público podia ser feita por um dispositivo de tipo político - os "encaixes" entre movimentos sociais e as instâncias estatais de garantia de direitos -, a revisão dos conteúdos do projeto coloca em cena, e como protagonistas, outros dispositivos de mediação. Analiso aqui dois deles: a gestão social e a violência.

Se o risco do gerenciamento de populações já estava previsto nos debates em torno da inserção dos movimentos populares no sistema político - e, ademais, desde Foucault (2008) -, a "expansão do mundo do crime" aparece nos anos 1990 como elemento novo nesse cenário normativo. A lógica instrumental do uso da força reaparece, em plena "democracia”, muito intensamente nas relações internas às periferias,

\footnotetext{
${ }^{14}$ Discuto a emergência do "mundo do crime" como instância normativa da "justiça” nas periferias em Feltran (2008; 2010a).

${ }^{15}$ Essa frustração é radicalmente notada em depoimentos, recorrentes na pesquisa entre jovens inscritos no "mundo do crime": "trabalhar para ser que nem o meu pai? Prefiro morrer cedo...”.
} 
a "violência urbana" se torna representação coletiva nas cidades e as taxas de homicídio explodem. Ora, não é necessário dirimir conflitos pessoais pelo uso da força privada, no limite letal, quando indivíduos se sentem inscritos numa ordem regida pelo direito; poder-se-ia recorrer à força pública, que numa ordem assim significaria proteção. Os relatos obtidos em pesquisa de campo, entretanto, partem do pressuposto contrário: pela experiência (em dimensão portanto anterior mesmo à consciência), sabe-se que as polícias não protegem a favela. Assim, seus moradores têm de se proteger por conta própria. A disseminação do uso privado da força não encontra outra explicação mais convincente. A expansão da violência interpessoal e sua especialização recente nas favelas de São Paulo, nas quais tribunais conduzidos pelo "mundo do crime" são legitimados como operação de justiça, parecemme, pois, intimamente relacionadas à frustração do projeto de inscrição dos "trabalhadores" no mundo do direito ${ }^{16}$.

$\mathrm{Na}$ virada do século, a corda estica. De um lado, tentase afrouxá-la pela ampliação das políticas compensatórias e de gestão da segurança, dos territórios e das populações, em geral na forma de convênios entre governos e organizações civis de base - muitas vezes antigos movimentos sociais - para a implementação de "projetos sociais": profissionalização, apoio familiar, atividades culturais etc. De outro, amplia-se a repressão nas fronteiras, tensionando as margens de filiação social e política e fazendo emergirem nelas mais e mais "suspeitos". O encarceramento de jovens adultos das periferias de São Paulo cresceu quatro vezes desde meados dos anos $1990^{17}$.

\footnotetext{
${ }^{16}$ Etnografias recentes demonstram que a queda das taxas de homicídio em São Paulo, nos anos 2000, se dá sobretudo por essa regulação interna ao "crime" (Feltran, 2010a; Marques, 2007; Hirata, 2009; Biondi, 2010).

${ }^{17}$ A população carcerária do estado de São Paulo passou de cerca de $40 \mathrm{mil} \mathrm{em}$ 1996 para mais de 150 mil em 2008. Sobre a associação dos dispositivos assistencial e repressivo, ver Almeida, De Lucca e D'Andrea (2009).
} 
O texto que segue apresenta a trajetória do Cedeca, uma ação coletiva originada em Sapopemba que, há mais de duas décadas, atua nessas tensões entre política, gestão e violência na zona leste de São Paulo. A narrativa do percurso da organização está dividida em quatro partes. Na primeira, contextualizo as origens do Cedeca como movimento popular, na reivindicação basista de garantia de direitos aos moradores do bairro. Na segunda parte, já em período pósditadura, aparece sua aposta na inserção institucional e os limites políticos que ela apresenta: a obtenção de convênios de atendimento situa a entidade, ao longo dos anos, numa posição subalterna de "burocracia de base" dependente de governos; as atividades de gestão se expandem na medida em que decresce a autonomia reivindicativa e a garantia dos direitos dos atendidos. Como reação a esse processo, na terceira parte da trajetória narro a tentativa de reativar as ações movimentistas do Cedeca, já nos anos 2000. Para tanto, cria210 se outra figura jurídica - o Centro de Direitos Humanos de Sapopemba -, que daria suporte político a um novo ciclo de protestos, especialmente voltado contra a violência policial nas favelas do distrito. A quarta parte da narrativa apresenta, então, a principal consequência dessa nova atitude: um ciclo de perseguições, ameaças, atentados e exílios de Valdênia, a principal ativista da organização. As notas finais propõem um diagrama de compreensão das relações entre as periferias e o mundo público no Brasil contemporâneo, em que coexistem a política, a gestão social e a violência.

\section{Cedeca e CDHS: uma trajetória}

\section{Origens: a aposta nos direitos}

Nascido no Parque Santa Madalena em 1991, o Cedeca foi consequência de quase duas décadas de atuação das Comunidades Eclesiais de Base (CEBs) no distrito, inspirada na "opção preferencial pelos pobres" característica da teologia 
da libertação. Sua fundação, amparada pela aprovação do Estatuto da Criança e do Adolescente no ano anterior, já significava um passo avançado na "luta política" dos movimentos populares: sua inscrição na gestão político-institucional, que se aprofundaria na década seguinte. Os quadros da organização, por isso, já contavam em seu nascimento tanto com militantes de base, moradores do bairro e religiosos, quanto com advogados, psicólogos e assistentes sociais profissionais. Antes mesmo de existir formalmente, entretanto, o Cedeca dava seus primeiros passos inspirado pela Campanha da Fraternidade (da CNBB) que, em 1987, teve como tema o "menor"18. A "comunidade" católica de Sapopemba, organizada por padres combonianos, resolveu encampar o tema pautando publicamente a situação de adolescentes do bairro inscritas em circuitos de exploração sexual nas ruas do centro da cidade. Propuseram-se, evidentemente, a "tirar essas meninas da rua". Aos 20 anos, Valdênia capitaneou a iniciativa de criar uma casa de acolhida para essas adolescentes no bairro. Ela própria se mudou para a "Casa das Meninas", como os militantes a chamavam - ou a "Casa da Luz Vermelha”, como a apelidara o estigma no bairro para iniciar o trabalho.

Dessa atuação de Valdênia e de um grupo de amigos do bairro, alguns anos depois nasceu o Cedeca. Mais ampla - agora defendia quaisquer meninos e meninas de Sapopemba que tivessem seus direitos violados -, a entidade já nascia tratando especificamente da questão da violência. $\mathrm{O}$ próprio nome do Cedeca, "Monica Paião Trevisan", homenageia uma das moradoras da Casa das Meninas, assassinada e esquartejada no final dos anos 1980. Reconhecia-se, no período, que a ação fundamental daqueles militantes era conhecer histórias de privação e violência nas favelas do bairro para denunciá-las em espaços ampliados de arti-

\footnotetext{
${ }^{18}$ Ver http:/ / www.cf.org.br.
} 
culação política. A publicização da privação ativaria a interrupção do ciclo de violência nesses territórios. As redes dos movimentos sociais do período, em transformação, ainda favoreciam articulações internas e o Cedeca se beneficia delas ${ }^{19}$. Um evento político narrado por Valdênia, ainda em 1988, dá ideia da dimensão que essa teia de contatos ainda se sustentava no período da Constituinte.

Era época de votação das emendas [à Constituição de 1988]. De todas as articulações feitas, houve vários movimentos da área da infância, em vários estados, e em São Paulo os meninos ocuparam a Sé. E do escritório da Pastoral do Menor, que ficava ali no prédio das Edições Paulinas, na praça da Sé, nós ligamos direto no Congresso para o Hélio Bicudo. Eles ligaram o autofalante do Congresso, durante a votação do artigo 227, e a garotada gritava da Sé! (Valdênia).

A operação simbólica de tradução política das privações, própria das narrativas dos movimentos sociais do período, é evidente: o movimento reunia as vozes dos meninos de Sapopemba àquelas de seus pares, outras tantas crianças e adolescentes brasileiros privados de direitos fundamentais, e daí carreava suas falas ao espaço público-político. A pressão de escutar as vozes dos meninos, naquele contexto de transformação do Congresso Nacional, "arrepiava até os mais conservadores”. Essa tradução simbólica traça uma linha de relação, recuperada aqui como nexo analítico, entre o menino da favela e o espaço público-político. Sendo por definição uma relação difícil e efêmera, apostavase na lei - o Estatuto da Criança e do Adolescente (ECA), o artigo 227 da Constituição etc. - como uma forma de

\footnotetext{
${ }^{19}$ Embora esse cenário de articulações posteriormente tenha se transformado muito, como discuto em Feltran (2006).
} 
conferir-lhe estabilidade. O centro da atividade política dos movimentos sociais do período encerrava-se nessa aposta (Feltran, 2005; 2007).

Nota-se, entretanto, que o Cedeca já foi fundado como um movimento de segunda geração. Se o discurso dos militantes preserva o basismo dos movimentos dos anos 1970, a estruturação das atividades institucionais estava longe da subversão passível de repressão oficial: ela já era prevista em lei ${ }^{20}$. Se os movimentos pioneiros exigiam a abertura de canais de participação no Estado, o Cedeca já era fruto da "democracia participativa". Se os primeiros queriam derrubar o regime, agora tratava-se, acima de tudo, de fazer cumprir a lei. Tentava-se inscrever o mundo dos adolescentes de favela no universo dos direitos e da democracia, já formalmente assegurados. O equacionamento da questão da violência era bastante peculiar naquele contexto: apostava-se que o "ciclo de violência" no qual os adolescentes atendidos estavam inscritos, nas favelas em que viviam, era fruto da privação de direitos. Esse ciclo seria superado pela aproximação desses sujeitos a uma arena pública em que a medida de existência do indivíduo fosse o direito. Sendo operadores dessa aposta, as ações coletivas como o Cedeca consideravam fundamental aos seus propósitos a articulação de um campo de pressão pela efetivação da cidadania. Os militantes, por isso, deixavam Sapopemba frequentemente para circular no ambiente sindical, partidário e religioso das esquerdas, agrupadas em São Paulo em torno do PT, que oferecia con-

\footnotetext{
20 “Art. 87 - São linhas de ação da política de atendimento: I - políticas sociais básicas; II - políticas e programas de assistência social, em caráter supletivo, para aqueles que deles necessitem; III - serviços especiais de prevenção e atendimento médico e psicossocial às vítimas de negligência, maus-tratos, exploração, abuso, crueldade e opressão; IV - serviço de identificação e localização de pais, responsável, crianças e adolescentes desaparecidos; V - proteção jurídico-social por entidades de defesa dos direitos da criança e do adolescente". (Brasil, 1990, grifo meu).
} 
teúdos programáticos ao campo movimentista. Em 1988, esse campo já obtivera sua primeira vitória significativa, a eleição de Luiza Erundina à prefeitura de São Paulo, sustentada basicamente pelos movimentos das periferias da cidade. O Cedeca já nascia, assim, em cenário extremamente favorável à obtenção de recursos para atendimento direto de meninos e meninas de Sapopemba. Passaria a atuar, na década seguinte, tanto nesses atendimentos quanto em conselhos setoriais de gestão das políticas para a infância e adolescência do município ${ }^{21}$.

\section{Inserção institucional: a expansão da gestão}

A ação coletiva que fundara o Cedeca consolida sua identidade institucional ao longo dos anos 1990. Os princípios da atuação movimentista seguiram operando; no entanto, inserida na lógica das políticas sociais, a perspectiva mais politizada própria de suas origens se traduz, paulatinamente, na 214 consolidação de uma expertise técnica. O Cedeca se tornaria, no final da década de 1990, fundamentalmente um espaço de referência - inclusive nacional - do atendimento a adolescentes das periferias inscritos no "mundo do crime". A tradução de uma ação coletiva reivindicativa rumo a uma organização que executa políticas sociais foi paulatina.

Como outros Cedecas ${ }^{22}$, a entidade tendeu à especialização na questão do "adolescente em conflito com a lei" (ou "autor de atos infracionais"). Trata-se daquele indivíduo que, tendo cometido infrações à lei e sido detido pela polícia, já foi julgado, condenado e encaminhado oficialmente

\footnotetext{
${ }^{21}$ Relevante notar que essa inserção já segue a setorialização própria da gestão das políticas sociais estatais. Se uma década antes podia-se falar "do movimento popular" ou "do movimento de favela", passa-se a falar agora de "movimento de saúde", "movimento de moradia", "educação", "infância" etc. (Feltran, 2005; 2007).

${ }^{22}$ Em 2008 havia nove Cedecas na cidade de São Paulo e outros quinze em diferentes estados do Brasil, articulados em torno de uma entidade nacional. Ver http:// www.anced.org.br.
} 
pela justiça para o cumprimento de uma "medida socioeducativa"23. Acompanhei esse atendimento, realizado pelo Cedeca para as medidas "em meio aberto", em pesquisa de campo. Descrevi com detalhe suas rotinas nas quais estão em pauta as interações entre profissionais, adolescentes e famílias atendidas, coordenação e equipes, Cedeca e governos; e, portanto, entre os distintos desenhos normativos do atendimento e a complexidade política que os acompanha (Feltran, 2008). Neste texto, será possível apenas apresentar uma síntese analítica desse estudo: em organizações sociais como o Cedeca, o que se chama atendimento consiste na tentativa de aproximar as representações do jovem favelado às do sujeito de direitos, a partir da articulação de uma tríade de conceitos: o vínculo, o encaminhamento e a rede de proteção.

$\mathrm{O}$ vínculo sintetiza a condição primeira e fundamental do atendimento. Em pesquisa, a atividade do Cedeca já me foi descrita como uma "pedagogia do vínculo". Trata-se do estabelecimento de uma relação específica entre o "educador social" (profissional contratado da entidade) e o adolescente atendido. De característica ao mesmo tempo pessoal e profissional, o vínculo supõe idealmente uma relação desigual: teria conteúdos técnicos na perspectiva do "educador", que manteria um "distanciamento profissional” em relação ao atendido, e de confiança pessoal na perspectiva do adolescente, que se engajaria assim nas atividades propostas. É consenso, entretanto, que o vínculo se ampara em relações densamente pessoais. Fundamentalmente privadas, essas relações conformariam o primeiro passo do adolescente favelado rumo ao mundo público do direito. A pressuposição, portanto, é a da desvinculação prévia entre esses mundos (o do "educador" e o do "adolescente"), exposta na des-

\footnotetext{
${ }^{23}$ O ECA prevê as seguintes medidas socioeducativas: "i) advertência, ii) obrigação em reparar o dano; iii) prestação de serviços à comunidade; iv) liberdade assistida; v) semiliberdade ou vi) internação" (Brasil, 1990).
} 
confiança, que aparece como sentimento prévio à relação e conforma a alteridade inicial do encontro ${ }^{24}$.

Sem o vínculo, o adolescente permaneceria, portanto, alheio ao direito. Construído o vínculo, ele pode ser encaminhado à esfera das garantias públicas. Se o "educador" é a linha de frente do atendimento, em sua retaguarda há psicólogos, assistentes sociais e advogados, que organizam o encaminhamento específico de cada caso. Esses "técnicos" (como são chamados) estudam a situação de cada menino e a partir de um repertório de atividades de educação, saúde, esporte, profissionalização, cultura e acesso à justiça, que responderiam às demandas prementes de seu caso, tentam ativar para ele espaços de chegada na chamada rede de proteção social. O Cedeca seria, portanto, idealmente um lugar de triagem e trânsito de demandas a esferas sociais e políticas mais amplas, um portal de acesso dos jovens às garantias legais do ECA. Nem tudo é assim tão simples, entretanto.

"Há muita contradição no trabalho, não é? Numa realidade como esta, ou como qualquer outra periférica em que o menino está em situação de medida socioeducativa, você não tem muito a oferecer. Você vai encaminhar para um curso, a escolaridade dele não permite. Isso sem contar que eles só falam gíria e muitos deles são tatuados, então ninguém quer receber. E eles estão muito próximos dessa rede do crime, que hoje dá uma grana muito boa... se você pegar aí uma média [de remuneração individual], é de mil reais por mês. É muito dinheiro. E você não consegue uma bolsa que ultrapasse duzentos. A escola também não quer ele... Ela diz que ele não tem perfil, que não se enquadra,

\footnotetext{
${ }^{24} \mathrm{O}$ papel social da entidade de atendimento seria, portanto, de mediação entre o universo privado (da interação face a face, mas também da favela, da violência) e o espaço público do direito (da cidadania, da democracia). Essa concepção do social é, por isso, inteiramente arendtiana (Arendt, 2003). Para a autora, entretanto, não há possibilidade da política nascer daí.
} 
que ele é rebelde, tudo cai sobre os meninos da medida, 'os LA'. Você não tem uma rede de saúde que permita fazer um diagnóstico de por que é que ele usa tanto a droga, por que a droga seduz tanto, você não tem. Você não tem uma clínica, você não tem nada que permita que esse menino possa sonhar ou buscar outra coisa. Então é muito complicado o trabalho." (Roberta, então coordenadora do Cedeca).

O depoimento expõe a fratura. E se confirma pelos anos de observação. O desenho normativo da política de atendimento que convenia o Cedeca encontra obstáculos em dois níveis: num primeiro, propriamente político, percebe-se que a rede de proteção social não funciona, ou melhor, que ela não existe como tal. A oportunidade de emprego exige ficha de antecedentes criminais, o posto de saúde não oferece tratamento para dependência química, o curso de informática é caro, a escola já expulsou aquele menino uma vez, os aprendizes em seleção pela Embratel devem ter o ensino fundamental completo. Na hora da entrevista, o menino só falou gíria. No primeiro dia na Frente de Trabalho, achou o serviço muito pesado. Quando preencheu a ficha do serviço militar, disse que não era voluntário. No exame físico, as tatuagens o barraram. Abandonou a Prestação de Serviços na escola, teve vergonha de varrer o pátio na frente dos colegas. Faltou à audiência no fórum, "vacilo"...

Quando o menino não é encaminhado para a "rede de proteção", o "crime" o desencaminha, como me disse um educador. Foi ao shopping depois de um assalto e torrou mil reais numa tarde. Varou a noite na viela fumando "uns baseados". "Deu fuga" a 120 km/h. na Avenida Sapopemba. Foi ontem "no salão" com a Patrícia. "Pegou" um carro com uma sanfona dentro, vendeu por cinquenta reais. Desceu para a praia em meia hora, numa 1100 (cilindradas, moto esportiva). As frases de caderno de campo, como o depoimento da então coordenadora do Cedeca, dão ideia 
da disputa simbólica entre os estímulos que um adolescente recebe para se vincular ao atendimento do Cedeca e aqueles que tem para permanecer no "crime".

As consequências dessa disputa na função mediadora do Cedeca são inevitáveis. Para estabelecer o vínculo inicial do atendimento, e sem poder encaminhá-lo, os técnicos têm que criar, no próprio âmbito interno à entidade, atividades que seduzam os adolescentes. É preciso ter ali "atividades" a oferecer: cursos de grafite, viagens à praia, apoio de advogados, oficinas de cavaquinho, sempre amparadas por "bolsas-auxílio" vinculadas à frequência. Ao mesmo tempo, se não for possível enviar o adolescente dependente do crack para um serviço especializado, há uma psicóloga na entidade que pode reunir famílias com problemas similares num grupo e dedicar parte de sua semana a isso. Se o programa de proteção a indivíduos ameaçados não é acessível, os técnicos da entidade auxiliam a família a se 218 mudar para a casa de um parente. Se não há vagas gratuitas para o curso de informática, o Cedeca pode alocar dez computadores doados na salinha do fundo. Um funcionário pode dar aulas à noite, como voluntário. Se os cursos do Senai exigem escolaridade elevada, com recursos da cooperação internacional pode-se montar uma padaria comunitária, um pouco menos equipada.

Assim, o Cedeca se insere num ciclo muito comum entre as entidades sociais das periferias contemporâneas: as organizações tendem a reproduzir internamente, por meio de convênios, o que falta na rede de proteção externa. Elaboram-se projetos de novos atendimentos, que geram novas estruturas de gestão (e nunca suprem sequer a demanda do bairro). Com o tempo, esses atendimentos passam a integrar o organograma da entidade. A pressão por ampliação desses atendimentos se traduz, então, numa pressão por expansão do âmbito gerencial da organização. Mais projetos a escrever, mais gente a contratar, rotinas mais 
complexas e burocráticas a gerir. Em 1991, o grupo de fundadores do Cedeca comemorou a doação de uma casa para iniciar seus trabalhos. Quando cheguei a Sapopemba, em 2005, esse grupo fundador já administrava cinco núcleos de atendimento no bairro. Em 2008, e a despeito da franca oposição do Cedeca à administração municipal, principal responsável pelo financiamento, seu atendimento já estava desdobrado em nove núcleos. As atividades dessas entidades, espalhadas pelo mapa do distrito, já envolvem hoje plantão jurídico, psicológico, educação de rua, acompanhamento de medidas socioeducativas, apoio familiar, grupo de mães, atividades culturais, atendimento a deficientes físicos, marcenaria, padaria, cabeleireiro, projetos ambientais, qualificação profissional, entre muitas outras.

Cada uma dessas atividades é mantida por um "convênio", firmado junto a governos ou ao chamado "terceiro setor". Sempre amparados por "projetos", esses convênios duram de alguns meses a dois anos, e a intermitência do repasse de recursos é sua marca distintiva. Sempre que cheguei ao Cedeca para um novo período de trabalho de campo, nesses cinco anos, projetos haviam deixado de existir, projetos haviam sido criados e a dificuldade dos encaminhamentos era mais notável.

Mesmo porque a expansão de uma entidade social, como de uma família ou empresa, significa a expansão de seu orçamento. Não necessariamente, entretanto, o número de atendimentos se amplia, pois captar recursos passa a ser prioridade até para manter os empregos de quem, com esforço, conseguiu fazer da militância uma garantia profissional. As atividades de escritório passam a tomar mais tempo; é preciso gerenciar toda a máquina de atendimentos ao mesmo tempo em que se planeja o ano seguinte, e o ciclo gerencial não tem fim. A consequência desse ciclo para as atividades políticas da organização é evidente. A expansão gerencial, nascida da dificuldade de mediar o trânsito 
ascendente das demandas dos jovens ao mundo público, inscreve o Cedeca em fluxo de vetor oposto. Dependente dos financiamentos, a entidade passa praticamente apenas a executar projetos cuja pauta é decidida nos editais criados pelos financiadores.

A tendência ao crescimento de organizações como o Cedeca, regular especialmente nas periferias mais consolidadas de São Paulo, desperta uma série de questões analíticas. A literatura já tratou dos contextos externos que condicionam esta expansão - profissionalização, setorialização, competição por recursos, "onguização" e tecnificação do associativismo civil - sob o marco das relações entre sociedade civil e Estado no período pós-autoritário ${ }^{25}$. Num outro registro, entretanto, é preciso notar que essa expansão, cuja justificação remete à garantia de direitos, representa de fato a contenção do público atendido aos limites internos às fronteiras das entidades comunitárias. O "projeto" cresce e os 220 meninos, que seriam encaminhados para fora dos limites da organização, acabam circulando pelos núcleos dele próprio. Cria-se internamente um ambiente em que são acolhidos, mesmo que precariamente; ainda assim, é melhor do que fora dali, onde são estrangeiros. Fronteira. Os limites orçamentários impostos pelos convênios criam, portanto, um espaço de ação social específico destinado aos jovens pobres e apartado de circuitos mais amplos. Se o menino não está em prisão ou em entidades de privação de liberdade (unidades de internação, clínicas de desintoxicação ou de saúde mental, abrigos etc.), ele fica contido neste circuito, o dos "programas sociais".

No início dos anos 2000, os limites que essa expansão burocrática do Cedeca trazia foram se tornando evidentes.

\footnotetext{
${ }^{25}$ Um estado da arte dessa bibliografia está em Dagnino e Tatagiba (2007). Sobre a questão da representatividade dessas associações, ver Gurza-Lavalle, Houtzager e Castello (2006).
} 
Estabeleceu-se entre a equipe técnica um conflito que opunha o grupo de militantes fundadores, que apostava num "Cedeca movimento social”, e o grupo de funcionários contratados (técnicos das políticas sociais), que enxergavam a organização como um espaço de atendimento, portanto de atuação profissional. O primeiro grupo construía a imagem do Centro de Defesa como uma instância político-representativa da população do bairro: o Cedeca deveria agir como sujeito político, carrear demandas de meninos favelados a espaços públicos ${ }^{26}$. O segundo considerava o Cedeca como instância capilar de atendimento das políticas sociais, aquela que executaria a demanda técnica dos programas estatais ou privados, não importa, junto ao seu público-alvo ${ }^{27}$. A tensão entre os grupos se manteve latente até a solução pacificadora ser tomada. Se os convênios são vitais para manter os atendimentos, se os atendimentos exigem formação técnica e se o Cedeca já está inserido em sua lógica, não seria o caso de tentar reverter o quadro. A inércia tendencial de quase duas décadas de evolução institucional já seria difícil de frear. Há, entretanto, que fazer coexistirem o atendimento e a ação política. Para tanto, considerou-se ser preciso criar uma outra organização, de características distintas do Cedeca dos convênios.

\footnotetext{
26 "Então, o que é que nós estamos falando: nós podemos ter o atendimento, mas esse atendimento tem que estar a serviço da ideologia e da visão da entidade. Porque alguns, até coordenadores, no ano passado falavam assim: 'mas de repente a gente está com um planejamento na semana, aí tem que lotar ônibus e ir para manifestações políticas. Isso não é massa de manobra?' Falei: 'Depende. Se você está só ocupando a garotada, é massa de manobra. Mas se você vem trabalhando a conjuntura com essa garotada, sem perder de vista a vida real deles, não é massa de manobra. Isso é cidadania." (Valdênia).

27 "Você vai contratar um educador, tudo bem. Não tem nem problema se você quer contratar alguém da comunidade para dar uma chance à comunidade. Só que você tem que assumir a responsabilidade de contratar essa pessoa. Porque se essa pessoa não sabe trabalhar, com certeza vai ter alguém sobrecarregado. Entendeu? Agora, para chamar educador de educador, a priori essa pessoa tem que saber Paulo Freire de trás para frente e de frente para trás. Aí você pode começar a pensar em chamar o cara de educador." (Clarice, psicóloga contratada).
} 


\section{Retorno à ação política}

Daí nasceu o CDHS, Centro de Direitos Humanos de Sapopemba. A ideia inicial não era a de uma divisão estanque, em que o CDHS fizesse política e o Cedeca a gestão dos atendimentos. No entanto, nos cotidianos do endereço que as entidades compartilham no Parque Santa Madalena, essa divisão de tarefas se processou sem muito alarde: o CDHS herdou, para sua equipe, quadros mais combativos e politizados, além de ter, por não assinar convênios, mais autonomia frente ao Estado para lançar ofensivas no debate público; o Cedeca permaneceu negociando os repasses de verba de convênios com os governos e fazendo atendimentos. Ambos passaram a atuar, portanto, de modo complementar entre ação política e gestão social. Os principais militantes fundadores do Cedeca, entre eles Valdênia, passaram a se dedicar ao CDHS a partir de 2001, e prioritariamente a ele depois de 2003. Quando cheguei a Sapopemba para iniciar

222 minha pesquisa, Valdênia deixava definitivamente a coordenação geral do Cedeca. Desde 2003, o CDHS progressivamente assumiu a tarefa de articular os movimentos de base do distrito, realizar a formação de novas lideranças, promover audiências públicas de denúncia - que traziam autoridades do Estado à favela - e formular ações judiciais das "violações de direitos" ocorridas no bairro. Reagindo aos constrangimentos da gestão, e ampliando o escopo de atuação do Cedeca - por também defender direitos de adultos -, o CDHS manteve uma equipe profissional mínima, de característica combativa e remunerada por financiadores politicamente afins ${ }^{28}$. A estratégia mostrou-se acertada. Um novo ciclo de ações públicas dos militantes de Sapopemba iniciou-se já nos primeiros anos da década, e se consolidou a partir de 2005. O tema eleito para esse ciclo

\footnotetext{
${ }^{28}$ A principal fonte de financiamento do CDHS foi a cooperação italiana católica, que a rede de contatos com a Congregação dos Combonianos permitia.
} 
de protestos foi a violência policial, e as ações públicas da entidade alcançaram impacto político relevante nos anos seguintes. "O CDHS gosta de mexer no vespeiro", disse-me uma de suas militantes.

O repertório contemporâneo de modalidades de ação política do CDHS - discutido com mais vagar por mim em outro texto (Feltran, 2010b) - elabora um continuum que, num polo, produziu ações autônomas de pressão de governos e da opinião pública nos moldes dos antigos movimentos de protesto e, no polo oposto, propôs ações institucionalizadas, internas ao sistema jurídico-político, nos moldes típicos das ações coletivas dos anos 1990 e 2000. Esse repertório respondia, de um lado, à efemeridade das ações de protesto e, de outro, ao enrijecimento contemporâneo dos canais de participação social na política instituídos pós-Constituição de 1988. A forma mais celebrada da ação política desse movimento no período foi a das "audiências públicas na favela", justamente a que propõe mais radicalmente a mediação entre a população favelada de Sapopemba, que o CDHS quer representar, e o sistema político institucional, do qual ele já é um ator instituído (e subalterno). Promotores, advogados, comandantes de polícia, deputados federais e mesmo o Procurador Geral do Estado chegaram a participar desses eventos, sempre dentro das favelas do bairro. O CDHS cumpria sua tarefa e todos estavam motivados.

\section{Ação política, reação violenta}

Mas a história não termina assim, nunca. O ciclo de denúncias políticas lançado pelo CDHS gerou reações violentas, tanto de policiais denunciados por abusos, quanto de setores do "mundo do crime" local. A partir do estabelecimento desse ciclo intensificaram-se as ameaças de morte a Valdênia, que já forçaram quatro exílios no exterior durante esta década; por medidas de segurança, ainda hoje ela não 
revela seu endereço nem guarda fotos de seus familiares em casa. Até meados de 2008, quando se mudou definitivamente de Sapopemba, a militante franzina permanecia sob proteção da Secretaria Nacional de Direitos Humanos.

Em sua carreira militante, a cronologia da repressão sofrida por Valdênia é longa. Dois episódios de violência sexual por retaliação a denúncias realizadas e algumas prisões em manifestações políticas já estavam em seu currículo quando fundou o CDHS. Entretanto, comprou suas maiores brigas levando adiante as denúncias de violência policial nas favelas de Sapopemba. Foram três casos de execuções sumárias cometidas por policiais, denunciados entre 1999 e 2003, e um começo de década sob intensas ameaças de morte. Nessa mesma época, chegou a sofrer dois atentados e teve de se exilar no exterior durante três períodos. Valdênia foi a primeira defensora de direitos humanos oficialmente protegida pelo Governo Federal e seu caso mobilizou atores 224 nacionais e internacionais da área: Anistia Internacional e a Secretaria Nacional de Direitos Humanos, além de inúmeros jornalistas de países diferentes. A resistência na militância, mesmo sob repressão, fez dela uma referência entre movimentos da área. Diversas organizações civis, frentes parlamentares de direitos humanos e governos, nos níveis municipal, estadual e federal, lhe prestaram homenagens ${ }^{29}$. Entre 2004 e 2007 as ameaças diminuíram.

Em setembro de 2007, época em que eu compilava dados sobre sua biografia para minha investigação, liguei a televisão à noite e a primeira imagem que me apareceu foi a de Valdênia. Tive tempo suficiente para ouvir sua última frase e já soube do que se tratava. Uma adolescente de

\footnotetext{
${ }^{29}$ Entre outras premiações, Valdênia recebeu da Câmara de Vereadores de São Paulo o título de Cidadã Paulistana e o Prêmio Nacional de Direitos Humanos, em 2003. Em 2005, recebeu o Prêmio Santo Dias de Direitos Humanos, oferecido pela Assembleia Legislativa estadual.
} 
Sapopemba, que cumpria medida socioeducativa no Cedeca, havia sido estuprada por seis policiais no Jardim Elba. O CDHS havia denunciado formalmente o caso em janeiro daquele ano; Valdênia havia acompanhado o andamento do processo e dois dos acusados tinham sido presos. Intimidações pessoais e novas ameaças culminaram com o episódio da reportagem de televisão - o nome de Valdênia havia sido encontrado, pela polícia, numa suposta lista de colaboradores do PCC (Primeiro Comando da Capital, principal facção criminosa de São Paulo), em um ponto de venda de $\operatorname{drogas}^{30}$. A informação foi divulgada pela grande impren$\mathrm{sa}^{31}$ e teve que ser desmentida depois:
"Coordenador do Programa de Proteção aos Defensores dos Direitos Humanos da Secretaria Nacional de Direitos Humanos, Fernando Matos esteve ontem em São Paulo para manifestar apoio à advogada Valdênia Aparecida Paulino, do Centro de Direitos Humanos de Sapopemba, na zona leste. Matos encontrou-se com autoridades paulistas e também definiu medidas para garantir a proteção da advogada e da entidade que ela preside. No dia 28, policiais da $3^{\text {a }}$ Companhia do $19^{\circ}$ Batalhão da Polícia Militar disseram ter apreendido em uma boca de drogas do Jardim Sinhá, na zona leste, uma agenda onde estaria grafado o nome "Dra. Valdênia", com registro de valores de $\mathrm{R} \$ 2$ mil e $\mathrm{R} \$ 3$ mil. [...] Uma série de acontecimentos recentes levaram entidades de direitos humanos a suspeitarem da apreensão. Desde 1999,

\footnotetext{
${ }^{30}$ Valdênia já havia, em 2005, se referido a outras "tentativas de criminalização" pelas quais havia passado.

31 "Advogada aparece em suposta lista do PCC. Um centro de distribuição de drogas, supostamente controlado pelo Primeiro Comando da Capital (PCC), foi estourado anteontem pela polícia no Jardim Sinhá, na zona leste de São Paulo. Os policiais disseram que encontram no local lista de beneficiados. Entre eles o nome de 'Dra. Valdênia'." (O Estado de S. Paulo, 29/09/2007).
} 
Valdênia já denunciou mais de 20 casos de arbitrariedades envolvendo policiais do $19^{\circ}$ Batalhão na zona leste."

(O Estado de S. Paulo, 9/10/2007).

Um ato de desagravo à Valdênia foi imediatamente proposto por um parlamentar petista e mais de trezentas pessoas compareceram. A acusação dirigida a ela foi retirada. A intuição dos organizadores do ato é explícita: politizar a acusação diminui a chance da violência retornar. A dos acusadores também: criminalizar a ação política é um modo de circunscrever seus atores como sujeitos não legítimos. Nas ações judiciais relativas ao episódio ficou reconhecida a falsificação da lista e a tentativa de incriminar Valdênia foi punida: os suspeitos da fraude foram indiciados. Na institucionalidade, a democracia resguarda seus princípios. As ameaças não pararam, entretanto; extra-oficialmente, a violência prossegue mediando as relações. A sede do Cedeca

226 e CDHS foi revirada pela enésima vez no final de 2007, e no ano seguinte. Em janeiro de 2008, Valdênia passou nova temporada no exterior; no final do ano mudou-se definitivamente de Sapopemba para iniciar vida nova longe de tudo aquilo, no interior do nordeste.

\section{Faces de um mesmo conflito: política, gestão e violência}

A partir dessas etnografias, tenho definido a política como o jogo de conflitos desencadeados na conformação da cena pública, em sua manutenção e transformação ${ }^{32}$. Essa noção geral precisa, entretanto, ser especificada quando se trata de um olhar analítico voltado para as margens da política contemporânea. Trajetórias como as do Cedeca auxiliam

\footnotetext{
${ }^{32}$ As principais referências teóricas para pensar esse conceito estão em Hannah Arendt e Jacques Rancière. Para o que chamo aqui de espaços públicos, ver os trabalhos de Cefaï (1996; 2007); Cefaï e Pasquier (2003); e, para o caso brasileiro, as relações entre cultura e política trabalhadas por Dagnino (2002) e Dagnino, Oliveira e Paufichi (2006).
} 
a tentativa, por demonstrar que, em mundos sociais como o brasileiro, cuja desigualdade é respaldada pelo funcionamento estatal, a política nunca se resume à disputa de poder em terrenos institucionais previamente demarcados (Estado, eleições, sociedade civil, políticas públicas etc.). No modus operandi dos atores, a pressuposição da desigualdade atravessa esses espaços e obriga a ação política a se repensar continuamente ${ }^{33}$. A política pressupõe nesses contextos, portanto, para além das disputas institucionais, um conflito anterior: aquele que se trava, no tecido social, pela definição dos critérios pelos quais os grupos sociais podem ser considerados legítimos (Ranciène, 1995). Só quem se legitima, e é legitimado, pode participar daqueles espaços. A construção da legitimidade social, portanto, está na base da constituição de um sujeito ou espaço público, e, portanto, do conflito político.

Sob o pano de fundo da trajetória narrada, podese perceber que a ação política não se limita às disputas entre ações coletivas constituídas em terrenos previamente demarcados (movimentos, partidos, conselhos, assembleias, prefeituras etc.) ou aos critérios do jogo democrático; ao contrário, a política nesse contexto se assenta também, e fundamentalmente, na disputa subjacente à própria instituição destes terrenos e sujeitos - os militantes de favela têm de constantemente forjar sua aparição como sujeitos, lidando com fronteiras impostas pela gestão e, no limite, pela violência. Um evento público como o descrito na abertura do artigo pretende transformar o córrego canalizado da favela do Parque Santa Madalena numa arena de discursos políticos. No entanto, essa arena efêmera só aparece, e por isso é rara, se a ação coletiva que a sustenta tiver sucesso na

\footnotetext{
${ }^{33}$ A ordem política não é estável, como a existência da lei poderia fazer crer. $\mathrm{Na}$ proposição de Veena Das (2007), a dominação contemporânea atua a partir de uma zona cinzenta entre lei e ilegalidade, contingencial e operada pelo Estado.
} 
construção de sua legitimidade tanto entre favelados quanto entre atores centrais do sistema político-institucional, ou seja, na mediação da relação entre a favela e os terrenos políticos instituídos.

Nada simples. Por isso trajetórias como as de Valdênia são objetos analíticos fundamentais - sem elas, moradores e deputados federais não ocupariam aquele espaço comum, o que paradoxalmente dificultaria a análise - explícita ali - das fronteiras que os separam. Sem tal mediação política, não haveria a reflexão deste artigo. Sem a ação da advogada, o lugar da política teria se mantido no território dos especialistas, bem longe da favela, nos escritórios e prédios públicos em que homens de negócio e políticos profissionais decidem. Tenho trabalhado com a noção de fronteira como categoria analítica para auxiliar a demarcação destas clivagens entre periferias e política, ou das margens da política. Ao mesmo tempo em que denota uma 228 separação, a categoria fronteira preserva a possibilidade de fluxos, controlados, entre as parcelas separadas. A metáfora da fronteira interessa, ainda, por preservar a noção de conflito, latente como política ou gestão em condições de estabilidade da linha que a demarca, mas passível de se tornar violência caso se radicalize, como inúmeros eventos tem demonstrado ${ }^{34}$.

A demarcação de fronteiras nas margens da política sustenta a restrição da legitimidade de grupos inteiros da população às margens da cidade. A possibilidade de ações coletivas baseadas nesses territórios agirem politicamente, portanto, é desbastada de saída. A história do Cedeca, tal como contada aqui, não é mais que a narrativa dessa busca por legitimidade, que lhe emprestaria estatuto político. O que ela faz notar são as fronteiras de contenção ativa

\footnotetext{
${ }^{34}$ Em maio de 2006 esses eventos deixaram um saldo de 493 mortos em uma semana, 450 atribuídos à "reação" policial. Ver Adorno e Salla (2007).
} 
da legitimidade pública, tanto pela gestão "democrática" dos convênios feitos "para pobres" quanto pela violência. Sugere-se, assim, um tipo específico de coexistência, nos planos do regime político e da sociabilidade primária, entre ordenamentos de lógicas internas distintas: o primeiro é o código universalista dos direitos e da política; o segundo é o código técnico da gestão social da diferença; o terceiro é o código instrumental da violência. Todos parecem ser constitutivos da reprodução de uma dinâmica social marcada pela associação entre democracia institucional e extrema hierarquização. Nas últimas décadas, o modo de fazer estes códigos coexistirem foi limitar a vida política a uma parcela da população, que no entanto age, como é próprio da ação de dominação, como se representasse o todo social. Para deixar democraticamente uma outra parcela da população (aqueles que o Cedeca e o CDHS tentam representar) fora da cena pública, ativam-se simultaneamente os mecanismos de gerenciamento das populações e, no limite, de incriminação. Um "bandido", afinal, é o menos legítimo dos cidadãos.

\section{Gabriel de Santis Feltran}

é professor do Departamento de Sociologia da UFSCar e pesquisador do Centro de Estudos da Metrópole e do Centro Brasileiro de Análise e Planejamento. Agradeço a meus interlocutores de pesquisa em Sapopemba pela convivência e aprendizado intensos desses anos.

\section{Referências bibliográficas}

ADORNO, S.; SALLA, F. 2007. "Criminalidade organizada nas prisões e os ataques do PCC”. Estudos avançados, São Paulo: IEA-USP, vol. 21, nº 61, pp. 7-29.

ALMEIDA, R. 2004. "Religião na metrópole paulista". Revista brasileira de ciências sociais, São Paulo: Anpocs, vol. 19, n 56, pp. 15-27.

2009. A Igreja Universal e seus demônios: um estudo etnográfico. São Paulo: Terceiro Nome/Fapesp. 
ALMEIDA, R.; D’ANDREA, T.; DE LUCCA, D. 2009. "Situações periféricas: etnografia comparada de pobrezas urbanas". Novos estudos Cebrap, São Paulo, $n^{\circ} 82$, nov.

ARENDT, H. 2003. "Reflexões sobre Little Rock". In: Responsabilidade e julgamento. São Paulo: Companhia das Letras.

AVRITZER, L.; NAVARRO, Z. (orgs.). 2003. A inovação democrática no Brasil. São Paulo: Cortez.

BAIERLE, S. G. 1992. Um novo princípio ético político: prática social e sujeito nos movimentos populares urbanos em Porto Alegre nos anos 80. Dissertação de mestrado em Ciência Política. Campinas: IFCH/Unicamp.

BEAUD S.; PIALOUX, M. 2003. Violences urbaines, violence sociale: genèse des nouvelles classes dangereuses. Paris: Fayard.

2009. Retorno sobre a condição operária: investigação em fábricas da Peugeot na França. São Paulo: Boitempo.

BIONDI, K. 2010. Junto e misturado: uma etnografia do PCC. São Paulo: Terceiro Nome/Fapesp.

BRASIL. 1990. Estatuto da Criança e do Adolescente. 1990. Lei nº 8.069, de 13 de julho. Dispõe sobre o estatuto da criança e do adolescente, e dá outras providências.

CALDEIRA, T. 1984. A política dos outros: o cotidiano dos moradores da periferia e o que pensam do poder e dos poderosos. São Paulo: Brasiliense.

CEFAÏ, D. 1996. "La construction des problèmes publics: définitions de situations dans des arènes publiques”. Reseaux, Paris vol. 14, n 75, pp. 43-66. . 2007. Pourquoi se mobilise-t-on? Les théories de l'action collective. Paris: La Découverte.

; PASQUIER, D. (org.). 2003. Les sens du public: publics politiques, publics médiatiques. Paris: Presses Universitaires de France.

DAGNINO, E. 1994. "Os movimentos sociais e a emergência de uma nova noção de cidadania”. In: (org.). Os anos 90: política e sociedade no Brasil. São Paulo: Brasiliense.

. 1995. "On becoming a citizen: the story of D. Marlene". In: BENMAYOR, R.; SKOTNES A. (orgs.). International yearbook of oral history and life stories. Oxford: Oxford University Press.

. 2002. "Sociedade civil, espaços públicos e a construção democrática no Brasil: limites e possibilidades". In: (org.). Sociedade civil e espaços públicos no Brasil. São Paulo: Paz e Terra.

; OLIVERA, A.; PANFICHI, A. (orgs.). 2006. A disputa pela construção democrática na América Latina. São Paulo: Paz e Terra.

; TATAGIBA, L. 2007. Democracia, sociedade civil e participação. Chapecó: Argos. 
DAS, V. 2007. "The signature of the state: the paradox of illegibility". In: Life and words: violence and the descent into the ordinary. Berkeley: University of California Press.

; POOLE, D. 2008. "El Estado y sus márgenes: etnografias comparadas". Cuadernos de antropología social, Buenos Aires: Facultad de Filosofia y Letras, $\mathrm{n}^{\circ}$ 27, pp. 19-52.

DOIMO, A. M. 1995. A vez e a voz do popular. movimentos sociais e participação política no Brasil pós-70. Rio de Janeiro: Relume-Dumará/Anpocs.

DUARTE, L. F. D.; HEILBORN, M. L. (orgs.). 2006. Família e religião. Rio de Janeiro: Contra Capa.

; GOMES, E. C. 2008. Três famílias: identidades e trajetórias transgeracionais nas classes populares. Rio de Janeiro: Ed. FGV.

DURHAM, E. R. 2005. A dinâmica da cultura. São Paulo: Cosac Naify.

FELTRAN, G. S. 2005. Desvelar a política na periferia: histórias de movimentos sociais em São Paulo. São Paulo: Associação Editorial Humanitas/ Fapesp.

2006. "Deslocamentos: trajetórias individuais entre sociedade civil e Estado no Brasil”. In: DAGNINO, E.; OLIVERA, A.; PANFICHI, A. (orgs.). A disputa pela construção democrática na América Latina. São Paulo: Paz e Terra.

2007. "Vinte anos depois: a construção democrática brasileira, vista da periferia de São Paulo". Lua Nova - revista de cultura e política, São Paulo: Cedec, nº 72, pp. 83-114.

2008. Fronteiras de tensão: um estudo sobre política e violência nas periferias de São Paulo. Tese de doutorado em Ciências Sociais. Campinas: IFCH/Unicamp.

. 2010a. "Crime e castigo nas periferias da cidade: repertórios da justiça e a questão do homicídio nas periferias de São Paulo”. Cadernos $C R H$, Salvador: UFBA.

2010b. "Na periferia da política: etnografia de uma ação coletiva das periferias de São Paulo, Brasil”. In: GEORGES, I.; TRIPIER, P. (orgs.). La démocratie participative au Brésil: promesses tenues et dynamiques ouvertes.

FERREIRA, M. I. C. 2003. Trajetórias urbanas de moradores de uma favela de um distrito de elite da capital paulista. Tese de doutorado em Sociologia. São Paulo: FFLCH/USP.

FOUCAULT, M. 2008. Segurança, território, população. Curso no Collège de France (1977-1978). São Paulo: Martins Fontes.

GUIMARÃES, N. A. 2004. Caminhos cruzados: estratégias de empresas e trajetórias de trabalhadores. São Paulo: Ed. 34. 
2009a. Desemprego, uma construção social: São Paulo, Paris, Tóquio. Belo Horizonte: Argvmentvn.

2009b. À procura de trabalho: instituições do mercado e redes. Belo Horizonte: Argvmentvn.

GURZA-LAVAlle, A.; HOUTZAGER, P.; CASTELlO, G. 2006. "Representação política e organizações civis: novas instâncias de mediação e os desafios da legitimidade". Revista brasileira de ciências sociais, São Paulo: Anpocs, vol. 21, n 60, pp. 43-66.

HIRATA, D. V. 2009. "Resumo da Apresentação". In: Seminário crime, violência e cidade. São Paulo: FFLCH-USP (mimeo).

MACHADO DA SILVA, Luiz Antonio. "Sociabilidade violenta: por uma interpretação da criminalidade contemporânea no Brasil urbano". Sociedade e Estado, Brasília, vol. 19, nº 1, 2004.

MARQUES, A. J. 2007. Dar um psicológico: estratégias de produção de verdade no tribunal do crime. In: Reunião de Antropologia do Mercosul, 2007. Porto Alegre: UFRGS. CD-ROM.

MARQUES, E.; TORRES, H. (org.). 2005. São Paulo: segregação, pobreza e desigualdades sociais. São Paulo: Ed. Senac.

MISSE, M. 2006. "Sobre uma sociabilidade violenta". In: Crime e violência no Brasil contemporâneo: estudos de sociologia do crime e da violência urbana. Rio de Janeiro: Lumen Juris.

PAOLI, M. C. 1995. "Movimentos sociais no Brasil: em busca de um estatuto político". In: HELLMANN, M. (org.) Movimentos sociais e democracia no Brasil. São Paulo: Marco Zero/Ildesfes.

RANCIÈRE, J. 1995. La mésentente. Paris: Éditions Galilée.

RIBEIRO, A. C. T.; GRAZIA, G. 2003. Experiências de orçamento participativo no Brasil. São Paulo: Vozes.

SADER, E. S. 1988. Quando novos personagens entraram em cena: experiências, falas e lutas dos trabalhadores da Grande São Paulo (1970-80). Rio de Janeiro: Paz e Terra.

TELLES, V.; CABANES, R. (orgs.). 2006. Nas tramas da cidade: trajetórias urbanas e seus territórios. São Paulo: Humanitas/IRD.

\section{Outros materiais:}

ANCED - ASSOCIAÇÃO NACIONAL DOS CENTROS DE DEFESA DA CRIANÇA E DO ADOLESCENTE. Disponível em <http:/ / www.anced. org.br>. Acesso em: 23/04/2007.

ARAGÃO, M. 2009. Consumo de não durável sobe16\% na baixa renda: classes D e E compram mais alimentos, diz pesquisa. O Estado de $S$. Paulo, 22 dez., p. B9. 
CF - CAMPANHA DA FRATERNIDADE. Disponível em <http://www. cf.org.br>. Acesso em: 25/06/2008.

O Estado de S. Paulo, 29/09/2007.

O Estado de S. Paulo, 9/10/2007. 


\section{MARGENS DA POLÍTICA, FRONTEIRAS DA VIOLÊNCIA: UMA AÇÃO COLETIVA DAS PERIFERIAS DE SÃO PAULO}

\section{GABRIEL DE SANTIS FELTRAN}

$\mathrm{O}$ artigo discute a relação contemporânea entre periferias urbanas e mundo político no Brasil, tomando como objeto heurístico a trajetória de mais de duas décadas de uma ação coletiva da zona leste de São Paulo. Argumento que a relação entre periferias e mundo público foi historicamente marcada pelo conflito. O percurso desse conflito, e de suas formas de contenção a partir dos anos 1970, faz ainda hoje coexistirem três dispositivos distintos, que na linha do tempo tiveram ênfases sucessivas: 1) a luta política, cuja lógica interna remeteu à aposta nos direitos da cidadania, central nas ações dos "movimentos sociais" desde os anos 1970 até o início dos 1990; 2) a gestão estatal e civil de grupos sociais das periferias, presente na lógica interna dos "programas sociais" a partir de meados dos anos 1990; e 3) a violência, presente ou latente na força repressiva vol- 
tada às periferias e regulada hoje, sobretudo, pelo próprio "mundo do crime".

Palavras-chave: Periferia urbana; Ação coletiva; Movimento social; Política; Violência.

\section{POLITICAL BORDERS, VIOLENCE LIMITS: A COLLECTIVE ACTION IN SÃO PAULO'S URBAN OUTSKIRT}

The article considers the history of more than two decades of a collective action for defense of social and civil rights in the eastern São Paulo. This trajectory gives empirical ground for a reflection on the relationship between contemporary politics and poor neighborhoods in Brazil. I argue that this relationship has always been marked by conflict. The course of this conflict has had three forms that coexist, which have succeeded each other in dominance: 1) political struggle for rights, central to the actions of "social movements" of the 1980s and 1990s; 2) social management, conducted by the

244 State and by local organizations, present in the internal logic of "social programs" from the years 1990; and 3) violence, present or latent in the police repression in urban outskirts and today mainly regulated by the "criminal world".

Keywords: Urban outskirts; Politics; Violence; Collective action; Social movement. 